\title{
Development of Software for Simulation of Hot Water Displacement in Porous Media
}

\author{
${ }^{1}$ A.A. Dare*, ${ }^{2}$ D. C. Uguru-Okorie, ${ }^{3}$ A. O. Abiola, \\ ${ }^{1,3}$ Department of Mechanical Engineering, University of Ibadan, Ibadan, Nigeria \\ ${ }^{2}$ Department of Mechanical Engineering, Landmark University, Omu Aran, Kwara State, Nigeria.
}

\begin{abstract}
The current energy situation has placed demand on exploitation of energy resources such as in geothermal reservoirs. Adequate exploitation of geothermal energy potential requires detailed evaluation of temperature profile in the medium. This work has thus developed a model to achieve this.

A model was developed based on the conservation of mass, momentum and energy. The governing equations were solved using Crank-Nicholson version of the finite difference technique. The software was designed using MATLAB 5.0, Visual Basic 6.0 and Microsoft Excel. The visual basic component provides a means for the user to input parameters for the simulation. MATLAB provides the main computation while Excel was used to display the results. The software was used to simulate hot water displacement in a porous medium.

The results obtained showed that fluid injected from the side of the reservoir medium responds slowly to changes in temperature distribution than when injected from the bottom.
\end{abstract}

\section{Introduction}

The apparent rapid depletion of the non-renewable reserves of oil and gas combined with their increasing costs have stimulated research of enhanced oil recovery and alternative energy resources such as geothermal energy.

Enhanced oil recovery involves ways of recovering oil from a reservoir after it must have been depleted while geothermal energy is mainly the form of energy obtained from heated rocks. There has been more interest in geothermal energy due to the fact that it is a form of renewable energy.

Potential sources of geothermal energy can be divided into three major systems: hydrothermal, geopressured, and hot dry rock. In hydrothermal systems, heat from near-surface sources such a magma body is transferred to porous media and to the fluid within that media by conductive and convective processes. In geopressured systems, fluid is trapped in a reservoir where it is subjected to extreme pressures and high temperatures. Finally, in hot dry rock, systems with low permeability are heated by near-surface sources. The first uses of geothermal resources were for cooking, bathing, and space heating of buildings.

A geothermal reservoir is the entire system of permeable rocks and the hot fluid trapped in that volume of rock. A reservoir is generally regarded as a porous medium due to the presence of pores in the rock matrix. The rock contains most of the heat energy, but fluid (water or steam) is necessary to carry the thermal energy to the surface for economic use.

Basically, the reservoir can serve the purpose of heat storage and waste-heat injection where aquifers are used as receptacles for heated fluid.

In order to exploit the full potential of a reservoir in terms of its domestic or industrial use, there is therefore a need to study the behaviour of fluid in such reservoir (porous media). In addressing this, a simulator is therefore developed in this work.

\section{Geothermal Reservoir Simulation}

Reservoir simulators are powerful tools for evaluating reservoir performances such as pressure and temperature distributions in a reservoir. They solve a set of mathematical equations that describe the behaviour of the fluid in the reservoir. There are several papers that discussed and reviewed existing reservoir simulators.

Bjorns-son and Bodvarsson [1] developed a multi-feed zone reservoir simulator that allows for calculations of downhole pressure, temperature and quality in reservoirs with an arbitrary number of feed zones. It can simulate fluid properties in a reservoir during both discharge and injection and evaluate internal flow and relative contributions of feedzones. Another multipurpose reservoir simulator was developed by Hadgu and Freeston [2]. The simulator can handle the flow with dissolved solids and gases and allow multifeed reservoir simulation when adequate information on feed zones is available. It also includes heat loss and different geometry of reservoirs. However, these two simulators do not include reservoir flows in their model. Takahashi [3] developed a reservoir simulator that was coupled with a reservoir flow. It can handle single and two-phase flows in the reservoir. He does not, however, consider distributions of density and viscosity of two-phase fluids in the vicinity of reservoir. Hadgu et al [4] stated that the coupled simulator is capable, for example, of 
determining pressure and mass flow rate versus time and evaluating power output scenarios. Reffstrup and Houbak [5], employed finite element analysis in the numerical simulation of the reservoir.

Peiffer et al [6], developed a new geothermometry approach which was coupled with numerical optimization, which gave a reasonable reservoir temperature prediction of the geothermal wells in regions where salt and fresh water mix. Helbig S and Zarrouk S. J. [7] developed and tested a new correlation for the measurement of two-phase flow in geothermal pipelines, which is based on separated flow model with time discrete liquid phase flow which gave a more accurate measurement over homogeneous flow models. Türeyen et al [8] presented a two-step stochastic simulation methodology for geothermal reservoir management by assessing the uncertainties in future reservoir pressure and temperature using history-matched lumped-parameter models. Gong et al [9] numerically investigated the effect re-injected water and the rate of injection on geothermal reservoir in an oil field and it was discovered that increase in re-injection rate of water enhanced oil production and minimum temperature level and rate of re-injection of water was required to stabilize the temperature of the geothermal reservoir.

Zarrouk S. J. and Moon H. [10] reviewed the conversion efficiency of geothermal power plant using 94 geothermal plants worldwide as case study.

\section{Basic Equations For The Model}

The basic equations used for the model are based on the conservation of mass momentum and energy principles as well as the equation of state. There are hereby discussed.

\subsection{Conservation of mass}

The conservation of the fluid phase is expressed in dimensionless terms by

$$
\nabla \cdot\left(\rho_{w} U\right)=-\frac{\partial}{\partial t}\left(n \rho_{w}\right)
$$

Where $\mathrm{n}$ is the porosity and $\rho$ is density

Porosity and density are in general functions of both pressure and temperature. The dependence on pressure of these two variables leads to a transient pressure response in the porous structure when the pressure is changed at the boundary.

Pressure and velocity distribution in the porous structure may be assumed to be obtained instantaneously after pressure changes at the boundary. This leads to the so-called Boussinesq approximation where variation in density in the mass conservation is neglected [5].

Using this approximation, the mass conservation equation (2) may be simplified to yield:

$$
\nabla \cdot(U)=0
$$

$\mathrm{U}$ is velocity of the fluid.

\subsection{Conservation of Momentum}

The Darcy equation describes conservation of momentum. The Darcy equation may be derived from general Navier-Stokes equation.

The dimensionless Darcy equation has the following form:

$$
U=-\frac{K}{\mu}\left(\nabla p+N_{L} T \nabla z\right)
$$

In this equation $\mathrm{U}$ denotes the dimensionless Darcy velocity with components $(\mathrm{u}, \mathrm{v}, \mathrm{w}) . \mathrm{K}$ is the permeability tensor with permeabilities in the $\mathrm{x}-, \mathrm{y}$ - and $\mathrm{z}$ - directions while $\mathrm{P}$ is the pressure.

$$
K=\left[\begin{array}{lll}
K_{x x} & K_{x y} & K_{x z} \\
K_{y x} & K_{y y} & K_{y z} \\
K_{z x} & K_{z y} & K_{z z}
\end{array}\right]
$$

Where, the magnitudes of permeability in the $x, y$, and $z$ component directions are specified. If the permeability is isotropic (equal magnitude in all directions), then the diagonal values are equal, $K_{x x}=K_{y y}=K_{z z}>0$, while all other components are 0 .

$\mathrm{N}_{\mathrm{L}}$ in equation (3) is a dimensionless convection parameter defined by

$$
N_{L}=-\frac{g^{*} \rho_{w o}^{*} \beta^{*}\left(T_{i}^{*}-T_{o}^{*}\right) H^{*} k_{o}^{*}}{\alpha_{o}^{*} \bar{\mu}^{*}}
$$


Where $\beta^{*}\left(K^{-1}\right)$ is the coefficient of cubical expansion for the fluid. $\mathrm{N}_{\mathrm{L}}$ may be named Lapwood's convection parameter. $\mathrm{N}_{\mathrm{L}}$ is a modified Rayleigh number.

\subsection{Conservation of Energy}

Energy conservation is expressed for both the fluid and solid phases. Energy transport by flowing fluid as reservoir as heat conduction in both the fluid and solid is considered.

Denoting heat capacity per unit volume of the fluid phase and saturated porous structure by $(\rho C)_{\mathrm{w}}$ and $(\rho C)_{e}$ where,

$$
(\rho C)_{e}=(\rho C)_{w} n+(\rho C)_{s}
$$

and $(\rho C)_{s}$ is the heat capacity of the solid phase, the equation describing energy conservation may be expressed as follows:

$$
\nabla \cdot\left(\Lambda_{e} \nabla T\right)-(\rho C)_{w} U \cdot \nabla T=(\rho C)_{e} \frac{\partial T}{\partial t}
$$

Where $\Lambda_{e}$ denotes the conductivity tensor defined by

$$
\Lambda_{e}=\left[\begin{array}{ccc}
1+c_{u} u & 0 & 0 \\
0 & 1+c_{u} v & 0 \\
0 & 0 & 1+c_{u} w
\end{array}\right]
$$

Here $c_{u}$ is the coefficient of proportionality between velocity in the $x-, y-$, and $z$ - directions and the coefficient of hydrodynamic dispersion $\lambda_{u}$. The dimensionless $\mathrm{c}_{\mathrm{u}}$ is defined by:

$$
c_{u}=\frac{c_{u}^{*}}{(\rho C)_{w}^{*} H}
$$

The dimensionless Darcy velocity $\mathrm{U}_{\mathrm{D}}$ can also be defined by

$U_{D}=N_{P E}=\frac{V^{*}}{H^{*} B^{*}} \frac{(\rho C)_{w}^{*} H^{*}}{\lambda^{*}}$

$\mathrm{V}^{*}$ denotes injection rate $\left(\mathrm{m}^{3} / \mathrm{s}\right)$.

$\mathrm{H}^{*}$ represent the horizontal length $\mathrm{X}$ of the cross section of the medium (m)

$\mathrm{B}^{*}$ represent the breadth $\mathrm{Y}$ of the cross-section of the medium (m)

$(\rho \mathrm{C})$ represent the Heat Capacity per unit volume of water $\left(\mathrm{KJ} . \mathrm{Kg} / \mathrm{K} . \mathrm{m}^{3}\right)$

$\lambda$ represent the coefficient of hydrodynamic dispersion

$\mathrm{N}_{\mathrm{PE}}$ represent local peclet number.

Hydrodynamic dynamic dispersion is a factor that compares the widths of the thermal fronts in the calculated and observed temperature distribution.

In this simulation a hydrodynamic dispersion of 1 is used.

$\lambda=\mathrm{C}_{\mathrm{u}} \mathrm{U}_{\mathrm{D}}$

Where $\mathrm{C}_{\mathrm{u}}$ is the coefficient of proportionality between velocity and hydrodynamic dispersion.

\subsection{Equations of state}

Viscosity and density are specified as functions of temperature.

$$
\mu=\mu(T) \quad \rho=\rho(T)
$$

The function $\mu(T)$ is obtained from standard tables and values of $\mu$ used in the simulation are obtained by a lookup procedure.

Dimensionless density is linearized with respect to temperature to obtain the coefficient of cubical expansion $\beta^{*}$ used in the calculation of the Lapwood number $\mathrm{N}_{\mathrm{L}}$. This linear relationship is expressed by

$$
\rho=1-\beta^{*}\left(T_{i}^{*}-T_{o}^{*}\right) T
$$
pressure is obtained:

By combining the mass conservation equation (1) and Darcy equation (2) the following equation in 
$\nabla \cdot\left(-\frac{K}{\mu}\left(\nabla p+N_{L} T \nabla z\right)\right)=0$

In numerical solution procedure the two second order partial differential equations given by (6) and (11) were solved with appropriate initial conditions and boundary conditions.

\section{Numerical Solution Of The Governing Equation}

Expanding the pressure equation (11) gives:

$$
\begin{aligned}
& \left(\frac{\partial}{\partial x} i+\frac{\partial}{\partial y} j+\frac{\partial}{\partial z} k\right) \cdot\left(-\frac{k}{\mu}\left(\frac{\partial P}{\partial x} i+\frac{\partial P}{\partial y} j+\frac{\partial P}{\partial z} k\right)+N_{L} T\left(0 i+0 j+\frac{\partial Z}{\partial z} k\right)\right)=0 \\
& -\frac{k}{\mu}\left(\left(\frac{\partial^{2} P}{\partial x^{2}}+\frac{\partial^{2} P}{\partial y^{2}}+\frac{\partial^{2} P}{\partial z^{2}}\right)+N_{L} T\left(\frac{\partial^{2} Z}{\partial z^{2}}\right)\right)=0
\end{aligned}
$$

Neglecting the contribution of the second term in the above equation, the pressure equation gives:

$-\frac{k}{\mu}\left(\frac{\partial^{2} P}{\partial x^{2}}+\frac{\partial^{2} P}{\partial y^{2}}+\frac{\partial^{2} P}{\partial z^{2}}\right)=0$

Expanding the first term of the energy equation(6) gives:

$$
\left(\frac{\partial}{\partial x} i+\frac{\partial}{\partial y} j+\frac{\partial}{\partial y} k\right) \cdot\left(\left[\begin{array}{ccc}
1+C_{u} U & 0 & 0 \\
0 & 1+C_{u} V & 0 \\
0 & 0 & 1+C_{u} W
\end{array}\right]\left[\begin{array}{l}
\frac{\partial T}{\partial x} i \\
\frac{\partial T}{\partial y} j \\
\frac{\partial T}{\partial z} k
\end{array}\right]\right)
$$

This gives:

$$
\begin{aligned}
& \left(\frac{\partial}{\partial x} i+\frac{\partial}{\partial y} j+\frac{\partial}{\partial y} k\right) \cdot\left(\left(1+C_{u} U\right) \frac{\partial T}{\partial x} i+\left(1+C_{u} V\right) \frac{\partial T}{\partial y} j+\left(1+C_{u} W\right) \frac{\partial T}{\partial z} k\right) \\
& \left(\left(1+C_{u} U\right) \frac{\partial^{2} T}{\partial x^{2}}+\left(1+C_{u} V\right) \frac{\partial^{2} T}{\partial y^{2}}+\left(1+C_{u} W\right) \frac{\partial^{2} T}{\partial z^{2}}\right)
\end{aligned}
$$

Furthermore expanding the second term of the energy equation gives:

$$
\begin{aligned}
& (\rho C)_{w}(U i+V j+W k) \cdot\left(\frac{\partial T}{\partial x} i+\frac{\partial T}{\partial y} j+\frac{\partial T}{\partial z} k\right) \\
& (\rho C)_{w}\left(\frac{\partial^{2} T}{\partial x^{2}}+\frac{\partial^{2} T}{\partial y^{2}}+\frac{\partial^{2} T}{\partial z^{2}}\right)
\end{aligned}
$$

Substituting these expansions back into the energy equation gives:

$$
\left(\left(1+C_{u} U\right) \frac{\partial^{2} T}{\partial x^{2}}+\left(1+C_{u} V\right) \frac{\partial^{2} T}{\partial y^{2}}+\left(1+C_{u} W\right) \frac{\partial^{2} T}{\partial z^{2}}\right)-(\rho C)_{w}\left(\frac{\partial^{2} T}{\partial x^{2}}+\frac{\partial^{2} T}{\partial y^{2}}+\frac{\partial^{2} T}{\partial z^{2}}\right)=(\rho C)_{e} \frac{\partial T}{\partial t}
$$

A finite difference method proceeds by replacing the derivatives in the differential equations by Finite difference approximations. This gives a large algebraic system of equations to be solved in place of the differential equation, something that is easily solved on a computer.

\subsection{Description of the Computer Program}

A software was developed for this simulation that incorporates MATLAB 5.0, Visual Basic 6.0 and Microsoft Excel 2003.

The main body of the program is written in MATLAB while Visual Basic 6.0 allows the program to receive input from the user. 
Microsoft Excel stores the result of each simulation for analysis.

The program is in modules and they are listed in the appendix.

\section{Results And Discussion}

The computation is done using the computer program written in MATLAB 5.0.

The input palettes are shown in Figs. 1 -3. A Summary of findings from parametric studies is presented in Table 1. A further discussion of the results is presented below.

Effect of changes in dimension of the cross-section: From the various results obtained, it was seen that the size of the porous medium affects the displacement of hot water in the porous medium.

For hot water injection from left, the highest temperature at the outlet of the medium was 0.135 at $\mathrm{x}=800 \mathrm{~mm}$ while the lowest temperature was 0.075 at $\mathrm{Y}=200 \mathrm{~mm}$.

For hot water injection from bottom, the highest temperature at the outlet of the medium was 0.99 when $\mathrm{X}=400 \mathrm{~mm}$ and $800 \mathrm{~mm}$ while the lowest temperature was 0.235 at $\mathrm{Y}=200 \mathrm{~mm}$.

Comparing this two results shows that the highest outlet temperature is obtained when hot water is injected from the bottom of the medium at $X=400 \mathrm{~mm}$ and $800 \mathrm{~mm}$, while the lowest outlet temperature was obtained when the injection is from the left at $\mathrm{Y}=200$.

This shows that to obtain a low outlet temperature, then the width $\mathrm{Y}$ of the medium should be as small as possible while to obtain a high temperature at the outlet, the Horizontal length of the medium should be varied as high as possible.

Effect of changes in Permeability: For variation in permeability during hot water injection from the left, the highest temperature at the outlet $=0.471$; at $\mathrm{Ky}=0.8 \mathrm{E}-10$; and the lowest temp $=0.087$ at $\mathrm{Kx}=0.8 \mathrm{E}-10$.

When injection is from bottom, the highest outlet temperature $=0.999$ at $=\mathrm{Ky}=0.8 \mathrm{E}-10$ while the lowest temperature $=0.209$ at $=\mathrm{Kx}=0.8 \mathrm{E}-10$.

Comparing these two results, it is seen that the highest temperature of 0.9999 is obtained at $\mathrm{Ky}=0.8 \mathrm{E}$ 10 when injection is from bottom and the lowest outlet temperature of 0.087 at $\mathrm{Kx}-0.8 \mathrm{E}-10$ when injection is from the left.

Effect of variation in $\mathbf{C u}$ : For variation in Coefficient of proportionality between velocity in $\mathrm{x}, \mathrm{y}$ and $\mathrm{z}$ directions and the coefficient of hydrodynamic dispersion $\mathrm{Cu}$,

During hot injection from the left, the Highest temperature obtained was 0.0637 for values of $\mathrm{CuX}=1.0$, $\mathrm{CuY}=0.1,0.5$ and $1.0 ; \mathrm{CuZ}=0.1,0.5$ and 1.0 ; While the lowest temperature obtained was 0.0062 at $\mathrm{CuX}=0.1$.

When the hot water is injected from the bottom, the highest temperature was 0.63 at $\mathrm{CuY}=1.0$ while the lowest was 0.261 at $\mathrm{CuY}=0.1$.

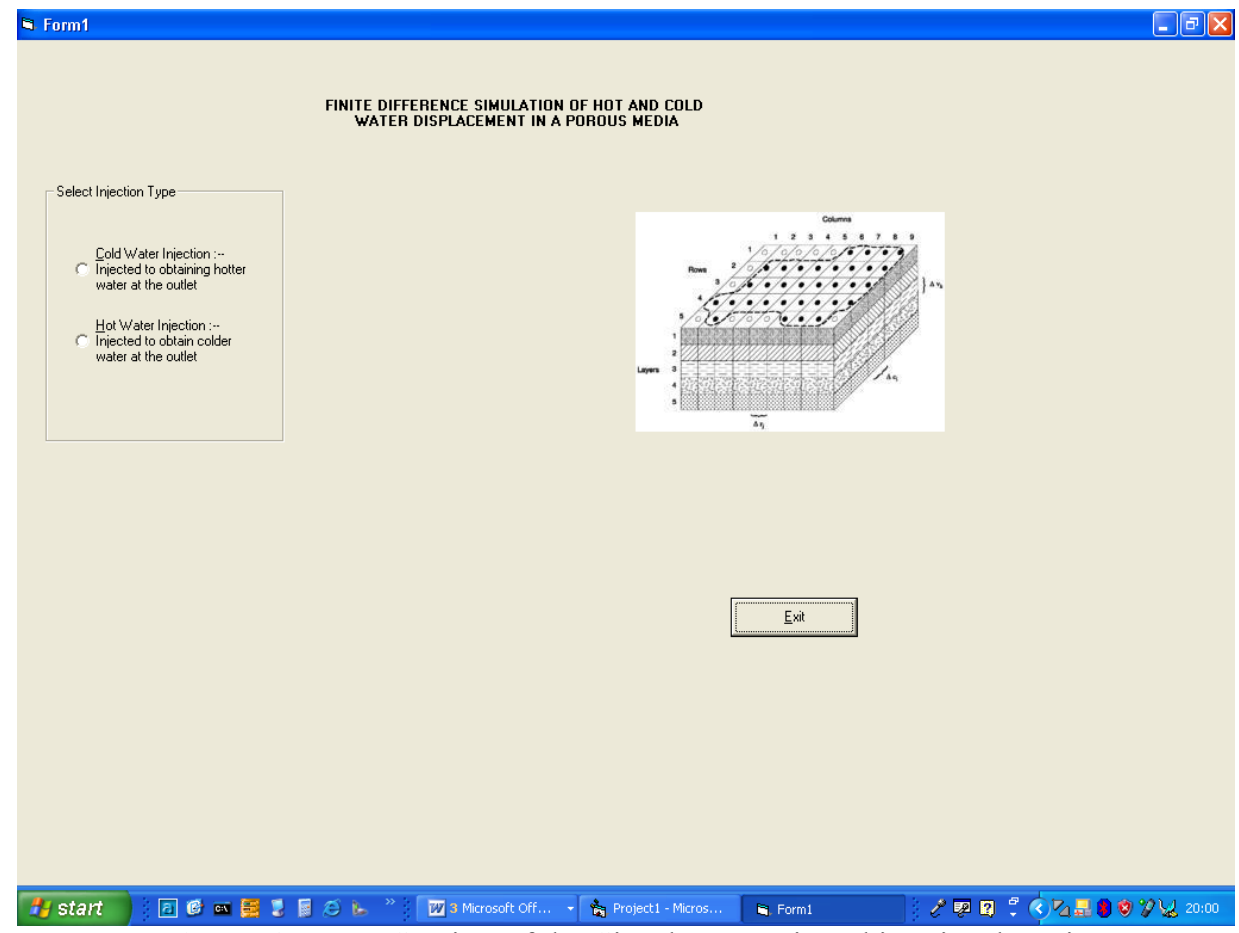

Figure 1: Entry Section of the Simulator Designed in Visual Basic 


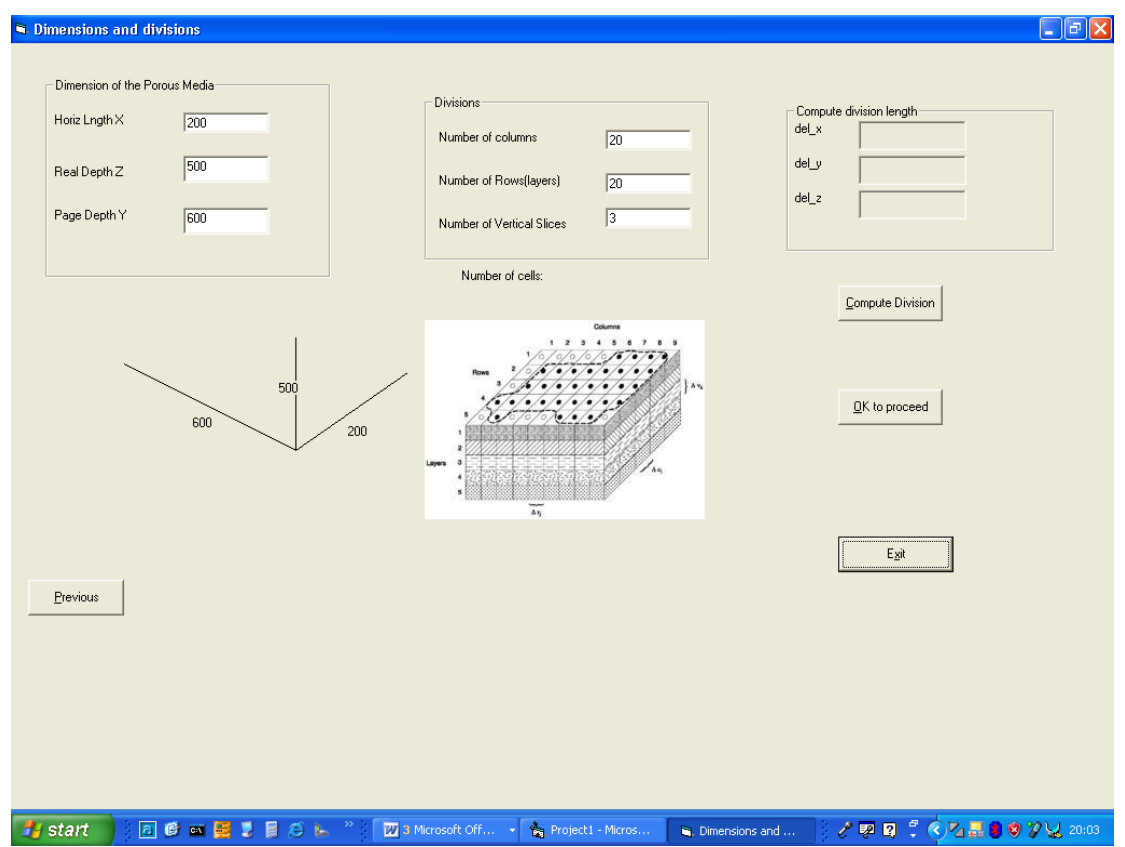

Figure 2: First Input Form of the Simulator

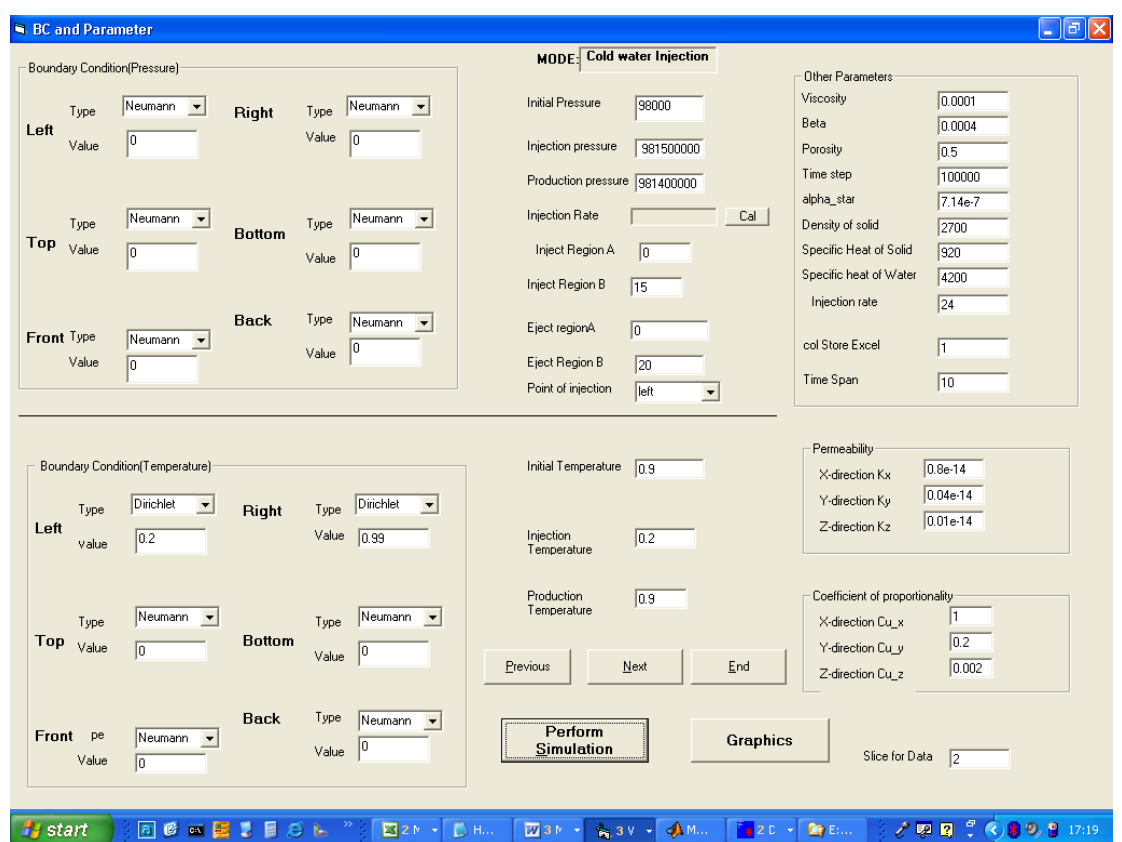

Figure 3: Visual Basic Graphical User interface (GUI) for entering Boundary Conditions and other Parameters 

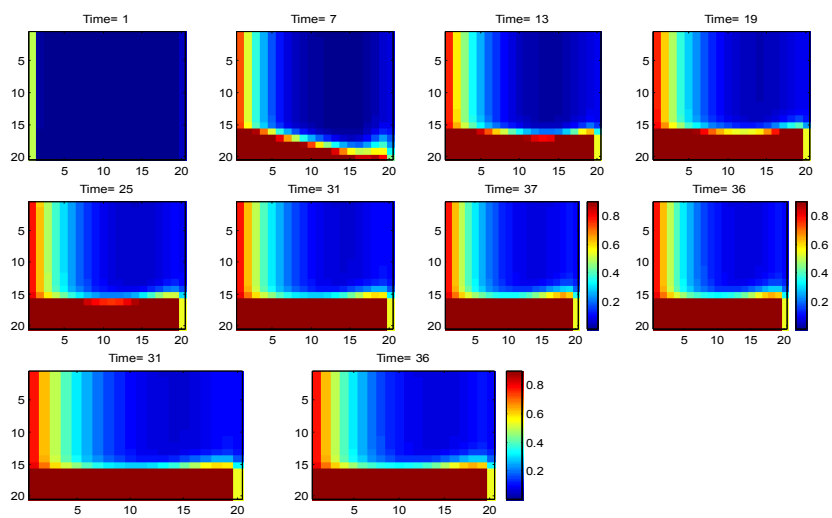

Figure 4: Horizontal plane of the medium showing the temperature profile of hot water injection from the left side
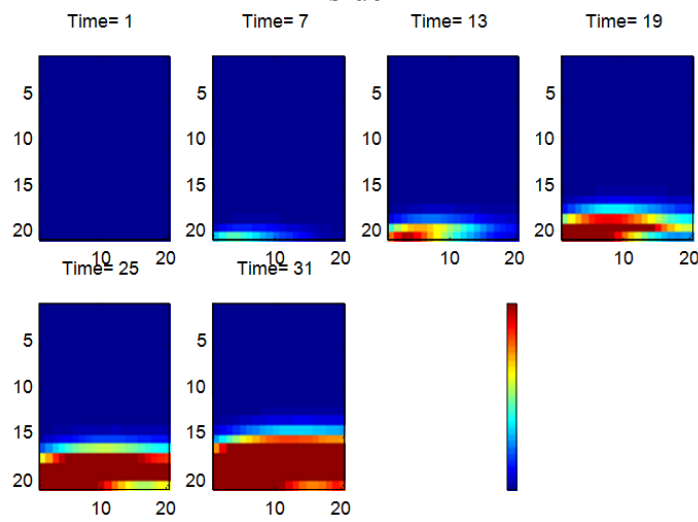

Horizontal plane of the medium showing the temperature profile of hot water injection from the bottom

The effects of the various parameters are stated in the table below

Table 1 Effect of Various Parameters on the Temperature Distribution

\begin{tabular}{|c|c|c|c|c|}
\hline $\begin{array}{l}\text { Type of } \\
\text { injection }\end{array}$ & $\begin{array}{c}\text { Injection } \\
\text { side }\end{array}$ & $\begin{array}{l}\text { Figure No } \\
\text { from } \\
\text { Graphical } \\
\text { analysis }\end{array}$ & $\begin{array}{c}\text { Parameter } \\
\text { observed }\end{array}$ & Observation \\
\hline \multirow[t]{8}{*}{$\begin{array}{l}\text { Hot water } \\
\text { injection }\end{array}$} & Left & 4.10 & $\begin{array}{l}\text { Variation of } \\
\quad \mathrm{X}\end{array}$ & $\begin{array}{l}\text { It is observed that as the horizontal length } \mathrm{X} \text { of the medium } \\
\text { decreases, the production temperature distribution decreases while } \\
\text { the injection temperature distribution increases }\end{array}$ \\
\hline & & 4.11 & $\begin{array}{l}\text { Variation of } \\
\text { Y }\end{array}$ & $\begin{array}{l}\text { As the width of the medium Y, decreases Production and Injection } \\
\text { temperature distribution also decreases }\end{array}$ \\
\hline & & 4.12 & $\begin{array}{l}\text { Variation of } \\
\mathrm{Kx}\end{array}$ & $\begin{array}{l}\text { For Production region, the temperature distribution increases as } \\
\text { permeability Kx decreases. At the Injection region - Temperature } \\
\text { distribution also increases for an decrease in permeability. } \\
\text { Moreover, it takes a longer period for the medium to achieve } \\
\text { steady state condition for very low permeability Kx. }\end{array}$ \\
\hline & & 4.13 & $\begin{array}{l}\text { Variation of } \\
\text { Ky }\end{array}$ & $\begin{array}{l}\text { Both Production and Injection region experience a higher } \\
\text { temperature distribution as permeability }(\mathrm{Ky}) \text { increases }\end{array}$ \\
\hline & & 4.14 & $\begin{array}{c}\text { Variation of } \\
\mathrm{Kz}\end{array}$ & $\begin{array}{l}\text { Both Production and Injection region experience a lower } \\
\text { temperature as permeability }(\mathrm{Kz}) \text { decreases. It was also observed } \\
\text { that Ky and Ky have the same temperature distribution at } \\
\text { permeabilities } 0.8 \mathrm{E}-13 \text { and } 0.8 \mathrm{E}-16\end{array}$ \\
\hline & & 4.15 & $\begin{array}{l}\text { Variation of } \\
\mathrm{CuX}\end{array}$ & $\begin{array}{l}\text { Temperature distribution at production and injection region } \\
\text { increases as Cux increases }\end{array}$ \\
\hline & & 4.16 & $\begin{array}{l}\text { Variation of } \\
\mathrm{CuY}\end{array}$ & $\begin{array}{l}\text { Variation of } \mathrm{CuY} \text { does not affect the production } \& \text { injection } \\
\text { temperature distribution for the preset-conditions in the medium }\end{array}$ \\
\hline & & 4.17 & $\begin{array}{c}\text { Variation of } \\
\mathrm{CuZ}\end{array}$ & $\begin{array}{l}\text { Variation of CuZ does not affect the production \& injection } \\
\text { temperature distribution for the preset-conditions in the medium. } \\
\text { Similar temperature distribution were observed for variations of } \\
\mathrm{CuY} \text { and } \mathrm{CuZ}\end{array}$ \\
\hline $\begin{array}{l}\text { Hot water } \\
\text { injection }\end{array}$ & Bottom & 4.18 & $\begin{array}{l}\text { Variation of } \\
\mathrm{X}\end{array}$ & $\begin{array}{l}\text { Increasing the horizontal length X causes the production } \\
\text { temperature distribution reach steady state temp faster. However, }\end{array}$ \\
\hline
\end{tabular}




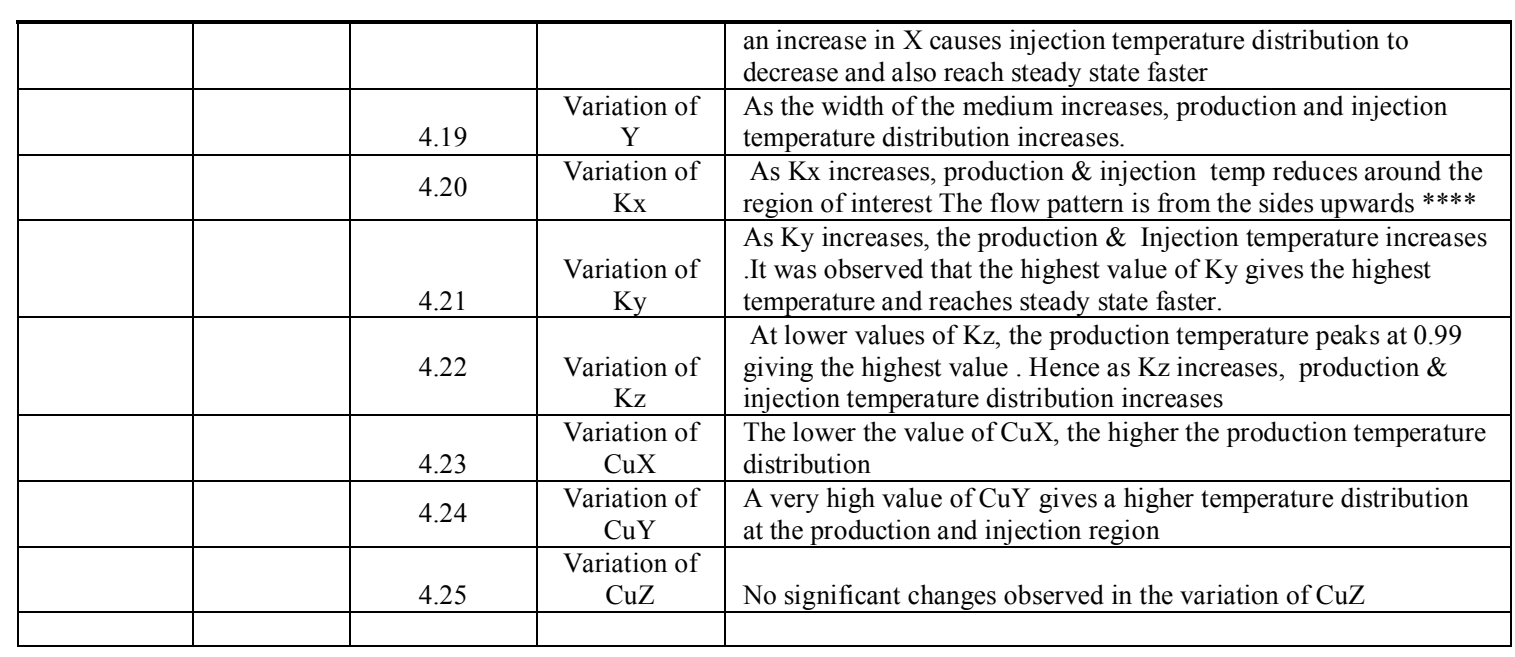

\section{References}

[1]. Bjornsson, G. and Bodvarsson, G. S. (1987) A Multi-Feedzone Wellbore Simulator. Geothermal Resources Council, vol. 11, pp. 503-507.

[2]. Hadgu, T. and Freeston, D. H. (1990) A Multipurpose Wellbore Simulator. Geothermal Resources Council, vol. 14, pp. 1279-1286.

[3]. Takahashi, M. (1999) Development of a Flow Simulator (WELCARD-V) Considering Inflow Performance and Wellbore Performance of Geothermal Well. Journal of the Geothermal Research Society of Japan, vol.21, pp. 341-352.

[4]. Hadgu, T., Zimmerman, R. W. and Bodvarsson, G. S. (1995) Coupled Reservoir-Wellbore Simulation of Geothermal Reservoir Behavior. Geothermics, vol. 24, pp. 145-166.

[5]. Reffstrup, J. and Houbak, N. (1985) A finite Element Analysis of Hot and Cold Water Displacement in Porous Media and Comparison against Experimental Results. John Wiley \& Sons Ltd. pp. 249.

[6]. Peiffer L., Wanner C., Spychher N., Sonnenthal E. L., Kennedy B. M., Iovenitti J. (2014). Optimized multicomponent vs. classical geothermometry: Insights from modeling studies at the Dixie Valley geothermal area, Geothermics, vol. 51, pp 154 - 169.

[7]. Helbig and Zarrouk J. S. (2012) . Measuring two-phase flow in geothermal pipelines using sharp edge orifice plates, Geothermics, vol. 44 , pp. $52-64$

[8]. Türeyen Ö. Í., Kirmaci A and Onur M (2014) Assessment of uncertainty in future performance predictions by lumped-parameter models for single-phase liquid geothermal systems, Geothermics, vol. 51, pp.300 - 311 .

[9]. Gong B., Liang H., Xin S. and Li K. (2013) Numerial studies on power generation from co-produced geothermal resources in oil fields and change in reservoir temperature, Renewable Energy, vol. 50, pp. $722-731$.

[10]. Zarrouk S. J. and Moon H. (2014) Efficiency of geothermal power plants: A worldwide review, Geothermics, vol. 51, pp. 142153. 